\title{
La noción de cuerpo y alma como centro en el Bruno de F.W.J. Schelling
}

\author{
The notion of body and soul like center \\ in F.W.J. Schelling's Bruno
}

MIGUEL ÁNGEL RAMÍREZ CORDÓN*

\begin{abstract}
Resumen: Cuerpo y alma son conceptos antinómicos que permiten establecer un juego de analogías donde decir cuerpo supone también decir lo real, ser, finitud, lo mortal, o el trabajo del entendimiento, mientras alma denota a su vez lo ideal, pensar, la infinitud, la inmortalidad, o el órgano de la razón. Con todo, seguir esta pista, la de ver grados distintos de conceptos opuestos recíprocamente, es tanto como conformarse con ver en el vínculo de los términos correlativos una «turbia unidad» meramente analítica. La cuestión por tanto es si ha de haber una unidad absoluta que pueda extraerse de la inseparabilidad de estos conceptos. A partir de este punto se deja introducir el concepto de centro. Sólo cuanto más se habita este centro, el hombre logra quedar incluido en esta unidad absoluta, y ser más auténticamente hombre.
\end{abstract}

Palabras clave: cuerpo, alma, astro, luz, centro, hombre.

\begin{abstract}
Body and soul are contradictory concepts that allow to establish a set of analogies where body means also real, being, finitude, mortal, or the work of understanding, while soul denotes the ideal, thinking, infinity, inmortality, ortheorgan of reason. Never theless, to follow this track, i. e. to seedifferent grades of concepts reciprocally op posed, forces to admit the existence of a «turbidunit»merelyanalytical in the link of thecorrelativeterms. The question therefore is if there has to be an absolute unit that could be extracted from the inseparability of these concepts. From this point we are allowed to introduce the concept of center. The more this center is inhabited, the more the man manages to remain included in this absolute unit, and to be more autentically man. Keywords: body, soul, star, light, center, man.
\end{abstract}

\section{Cuerpo y alma separados}

En las primeras páginas del Bruno los dos puntos de vista que aparecían en el Sistema del Idealismo trascendental, el subjetivo y el objetivo, el ideal y el real, continúan aquí igualmente contrapuestos: lo ideal está emparentado con las verdades imperecederas, iguales a sí mismas. Cuando es el hombre, en cambio, el que trata de aprehender la verdad, ésta

Fecha de recepción: 05/06/2016. Fecha de aceptación: 20/07/2016.

* Universidad Complutense de Madrid. Doctorando en el Departamento de Historia de la Filosofía. Correo electrónico: miguelramirezcordon@gmail.com. 
queda deslucida, las verdades eternas pasan a estar «subordinadas» con respecto al aparato de intelección humana, que no puede asumir la verdad de un modo inmediato ${ }^{1}$. El Anselmo del diálogo no se conforma con ello, y sugiere si no pudieran tratar de llegar a entender la verdad no como una mera copia de aquella verdad originaria, sino apropiarse de esa verdad que es tan clara como deba serlo Dios mismo². En el diálogo inicial de Anselmo y Alejandro, parece que el hombre podría encontrar en la bocamanga el modo de llegar a ascender a aquella verdad suprema. Dado que las cosas tal como aparecen bajo el punto de vista humano están desustanciadas, debe existir algún modo que paulatinamente permita llegar a una verdad cada vez más depurada. Esta estrategia consistirá en acercarse a los arquetipos, el primero de los cuales es la naturaleza ${ }^{3}$. La naturaleza es de algún modo el escenario perfecto donde se muestran los «modelos eternos de las cosas», a los cuales se les debe atribuir un parentesco directo con Dios. Cuando lo que se está observando por tanto no son los objetos de la naturaleza, sino su vínculo con las verdades eternas, el conjunto del «arte viviente» dibujado por Dios debe ser la primera pista para hallar la relación directa entre las cosas y la verdad o la belleza eterna.

No se está hablando de otra cosa que del concepto. El concepto es el órgano mediador que pone directamente en relación la verdad eterna y el estatuto de las cosas por medio de modelos ideales que suponen la plataforma necesaria de la adecuación entre los modelos de la verdad implícitos en las cosas y Dios ${ }^{4}$.

El papel del concepto como mediador entre Dios y las cosas no es más que un modelo ideal. Establecido el modelo de la perfección absoluta de Dios, y el procedimiento a que está sometida la razón para llegar a inteligir la idea de Dios, se pasa a un orden de consideración diferente. Quien aparece aquí es el hombre, ámbito específico de la finitud, al cual en cambio deben de serle accesibles las verdades eternas, así como la obra de arte, en su particularidad finita, obtiene a través de los modelos la forma de Dios a través de una representación. De entre los dos modos de conocimiento posibles, la filosofía y el arte, es éste último el que le queda reservado al hombre como modo de aproximación más óptimo a la verdad ${ }^{5}$. Los hombres solo ven copias de aquella verdad impertérrita, y deben de recurrir a algo externo que pueda aproximarles a lo eterno.

Es fundamental a este respecto el papel que juegan los misterios. Los misterios tienen el cometido de limpiar el alma y hacerla retomar el conocimiento de la verdad que ya tenía en otro momento. El alma tiene la disposición de albergar la verdad, ya la contuvo en su interior, pero por una falta debió caer. Si el alma podía contener en sí la verdad, que es la unidad por antonomasia, el alma entonces no debía tener partes diferentes entre sí, ella misma tenía que ser unidad. Si ahora debe purificarse es porque es partes extra partes, es materia, es cuerpo, y debe acarrear ese cuerpo con el que debe alimentar su alma con la verdad, para lo cual debe rememorar lo que era en otro momento, precisamente a través de

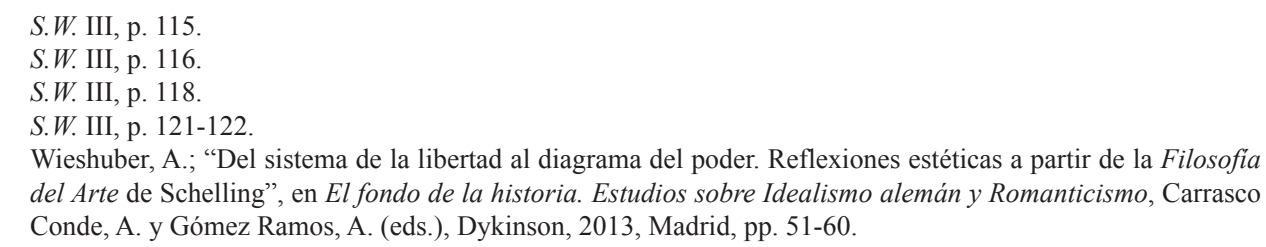
del Arte de Schelling”, en El fondo de la historia. Estudios sobre Idealismo alemán y Romanticismo, Carrasco Conde, A. y Gómez Ramos, A. (eds.), Dykinson, 2013, Madrid, pp. 51-60. 
una institución, es decir, no solitariamente, sino por medio de una organización social, pues al fin y al cabo el alma depende de un cuerpo inscrito en el espacio que hace que tenga unas partes a continuación de otras, y que permite a su vez la coexistencia de otras partes a continuación de otras partes, los cuerpos de otros individuos.

Los misterios enseñarán cómo el hombre debe limpiarse hasta llegar a alcanzar la verdad, y la mitología es el lenguaje por medio del cual deben ser transmitidos estos contenidos. De los misterios, del modo como debe ir llegándose a la verdad, debe encargarse el filósofo; la mitología, el lenguaje que debe destilar este particular mecanismo de conocimiento, le está reservado al poeta. Si bien la filosofía puede por sus propios medios llegar a conocer la verdad, no así el filósofo, ente finito que arrostra un modo infinito de conocer, inconmensurable con su propia naturaleza. Así, la filosofía, en manos del hombre, deberá convertirse en mitología.

En el momento en el que se comprueba el fracaso de poder llegar a ostentar el conocimiento del absoluto, el momento en el que los interlocutores resuelven que no queda más remedio que producir bellas imágenes del Absoluto que pueda dar una remota idea de lo que el Absoluto es, sin aspirar nunca a tocar siquiera el halo más cargado de herrumbre de su luz, aparece la diferencia y la oposición de los términos antinómicos, tal como muerte e inmortalidad, finitud e infinitud, o cuerpo y alma. Por lo mismo, arranca también en este punto un debate donde lo que se introduce es el modo de trabajo del entendimiento en el análisis de las diferencias, necesario para llegar a la unidad verdadera ${ }^{6}$.

En el análisis que abre la relación de la oposición y la unidad, se debate qué papel puede tener «lo Primero». Si se coloca lo Primero como lo prioritario, lo Primero no podrá evitar encontrar frente a sí algo que se le oponga, pongamos por caso lo segundo, y aquello derivado se opone a la unidad de lo Primero introduciendo la dualidad. Una unidad como esta, afirma Luciano, es una unidad «enturbiada por la diferencia» ${ }^{7}$. El camino que debe emprenderse pues para hallar una unidad auténticamente pura, es entender que siempre ha de haber una unidad absoluta, lo primero de donde nunca podría arrancar la sucesión de la multiplicidad de los subsiguientes números. Esta unidad por tanto comprendería en ella lo Primero y la contrariedad generada por la aparición de la oposición que estaba siendo invocada por la pretendida presencia incólume de lo Primero. No se trataría de la unidad lábil del "uno", sino más bien la del "cero". Dejaríamos así de tener dos términos opuestos entre sí, tal como lo está lo primero y lo segundo, lo infinito y lo finito, el alma y el cuerpo, y deberíamos de ver en el horizonte un tercero bajo el que se subsumiera la identidad de la unidad (lo Primero, el alma, si se quiere) y la diferencia (lo segundo, el cuerpo). Esto tercero no es en modo alguno lo que sucediera aritméticamente a lo segundo, sino un tercer término que no tiene por qué estar en relación aritmética con lo primero y lo segundo, sino que puede entenderse como lo que se encuentra en la situación de peraltación de las unidades matemáticas relacionales. Aquella unidad absoluta no se coloca frente a nada, sino que engloba la totalidad de oposiciones sin ser propiamente la totalidad ${ }^{8}$.

6 S.W. III, p. 131.

7 S.W. III, p. 132.

8 S.W. III, p. 135. 
La oposición de lo ideal y lo real es en el diálogo la primera de todas, pero pese a ser la oposición prioritaria, no puede entenderse sin su fundamento, que es justo el del pensar y el intuir, que en cambio no pueden ser tenidos como un grupo separado del primero, sino que es idéntico a lo ideal y a lo real respectivamente. Así como ocurría con la unidad y la diferencia, lo ideal está determinado gracias a la oposición que mantiene con lo real, siendo idéntico el caso que nos ocupa con respecto al pensar y al intuir, lo infinito y lo finito, o el alma y el cuerpo, y así sucesivamente 9 . En el caso del intuir y el pensar, el concepto tiene la facultad de recoger la multiplicidad de las diferencias bajo una unidad integradora, sometiendo lo diferente a lo indiferente. Cualquier particular, lo cual recibe la intuición por medio de la recepción sensible de los objetos externos, aparece reunido en el concepto como una unidad finita, así como una colección infinita de otras unidades particulares pueden pasar a ser registradas por el concepto en una línea infinita de determinaciones, de modo que la finitud nunca asumiría tal nomenclatura de no tener sobre sí la ilimitada determinación de un pensar infinito que ciñese el campo específico de lo que la cosa pueda ser. Hasta ahora estaríamos en efecto moviéndonos en torno a dos polos contrapuestos, el de la intuición y el concepto (o también, el cuerpo y el alma), de modo que aunque uno de ellos sea la facultad de lo infinito, el concepto, en cambio, está sometido de algún modo a lo particular de la intuición, a lo que debe atribuir su realidad. El resultado de esta mezcla sería que el infinito estaría tan limitado como lo finito. Con relación a aquella unidad absoluta, aquel "cero" que reunía lo "primero" y lo "segundo", es en este punto la idea la que engloba, en esta teoría de conjuntos, lo ideal y lo real, el pensar y el intuir, el concepto y lo particular, la infinitud y la finitud, el alma y el cuerpo ${ }^{10}$. De esta idea absoluta donde se reúne la totalidad «de los conceptos eternos de las cosas» ${ }^{11}$, es la filosofía la encargada de determinar cuál es su lugar y cuál el modo de llegar a ella.

Schelling nos recuerda que, así como en el hombre la razón se extiende y se desborda sobre toda la realidad, en esta criatura la razón «está subordinada a la intuición en la intuición $\mathrm{y}$ al entendimiento en el entendimiento» ${ }^{12}$. El «absoluto absoluto» ${ }^{13}$, como llama Schelling a esta unidad absoluta donde para ella no hay diferencia en la distancia que en efecto hay entre la oposición de lo uno y de lo otro, no opera del mismo modo bajo las condiciones humanas de conocer, donde lo ideal queda reducido a mera posibilidad, y lo real a lo dado en el tiempo ${ }^{14}$. Los conceptos que elaboramos en el órgano del entendimiento se encuentran en una trama de oposiciones, donde no es nunca posible llegar al estadio último en el que reposa la idea, la unidad suprema de todas las diferencias, y no podemos nunca llegar a decir de ella más que debe ser, sin poder por ello residir armónicamente en su confluencia. Nuestros conceptos son remedos de las ideas originales, están ajustados quizá a la realidad, pero son postizos con respecto al «absoluto absoluto». Las únicas unidades por tanto de las que podemos hablar es de aquellas donde se produce la subsunción de lo particular a lo general. Una vez más, la filosofía en boca del ser humano se convierte en mitología ${ }^{15}$.

\footnotetext{
9 S.W. III, p. 136.

10 S.W. III, p. 142-143.

11 S.W.III, p. 139.

12 S.W. III, p. 196.

13 S.W. III, p. 139.

14 S.W. III, p. 140.

15 S.W. III, p. 139.
} 


\section{Cuerpo y alma como acceso a la cuestión del hombre}

Los interlocutores tendrán a partir de ahora que imaginarse que Dios fuera parecido al mecanismo por el que lo infinito, el espíritu, reuniese en sí la esencia entera de todos los particulares, y que las cosas pudieran ascender a esta infinitud del concepto, pues es solo gracias a esta infinitud que lo finito puede ser lo limitado, encontrándose de este modo ajustado a su propia esencia, tal como si en ese movimiento, Dios gustase de abajarse y mezclarse con las cosas sometidas «a las condiciones del tiempo» ${ }^{16}$. Pero esto no es más que una metáfora. Descubierta esta auténtica verdad, los cuatro personajes del libro ceden a la solicitud de Luciano y se lanzan a conocer cómo funciona la conciencia, regresan todos al punto de vista exclusivamente humano ${ }^{17}$.

Así como el "cero" era el punto de indiferencia del "Primero" y del "segundo", o como la idea es el punto supremo respecto de lo ideal y lo real, del concepto y lo particular, en el ámbito de las facultades humanas es el saber el punto de indiferencia que mantiene ligados el pensar y el intuir, el alma y el cuerpo. El saber por tanto, como ecualizador del pensar y del intuir, se convierte en la unidad de la conciencia, en el substrato que actúa como producto de la unidad de cada una de las facultades cognitivas humanas. Esta conciencia es una unidad, la del pensar y el intuir, pero no es una unidad absoluta sino derivada.

Si la conciencia es derivada, una unidad primera, pero que debe tener todavía algún elemento allende su naturaleza substancial, el saber, que actúa como aglutinador de lo que la conciencia pueda llegar a conocer por medio del intercambio que mantienen la forma y la materia, el pensar y el intuir, debe igualmente ser «una unidad relativa» ${ }^{18}$. El saber lo es de algo, de algún objeto, del contenido que posibilita la relación del pensar y el intuir, el concepto y la intuición. Aquello que todavía no es saber, que no es aún conclusión de nada, es aquello de lo que aún no se tiene noticia, es el ser. El ser es una presencia, un aliquid del que solo constatamos su apariencia, sin conocer aún su esencia, su quid. El ser es algo aún relativo, tanto como lo es el saber, que es una unidad del concepto y la intuición solo cuando puede afirmar que sabe, pero nada puede saber sin previamente detenerse en aquello todavía desconocido ${ }^{19}$. El "cero" que actuase pues como unidad de la unidad de la conciencia, este «absoluto absoluto» radicado con todo en la naturaleza humana, sería la conciencia absoluta, respecto de la cual el saber resultaría ser algo derivado. Pero así como se ha expuesto que es imposible conocer aquello que es trascendente con respecto a lo inmanente como no sea negativamente, así como no puede haber trasvases entre los géneros, y cualquier resultado en este sentido sería irracional, como le ocurre a los números que se deducen de la relación inconmensurable que se da entre la diagonal y el lado de un cuadrado, en cambio no debería generar conflictos llegar a conocer aquello absoluto que se da dentro de los límites humanos mismos. Separarse del modo particular de conocer las diferencias limitadas, conservar la unilateralidad del modo de proceder de la intuición y el pensar, pero desde ahí llegar al punto en el que se aprehende la manera como la razón actúa absolutamente, deslavazada de toda relatividad, eso es conocer el modo como

16 S.W. III, p. 148.

17 S.W. III, p. 148.

18 S.W. III, p. 151.

19 S.W. III, p. 151. 
opera el punto absoluto de la conciencia, esto es, el punto más elevado de la potencia intelectual en grado sumo del hombre. A ello Schelling lo denomina "intuición intelectual".

A partir de este punto supremo de la conciencia, puede entenderse el origen de la conciencia particular y de la división que se practica a su vez en ésta entre su capacidad de intuir las cosas del mundo y la tarea de referir a cada cosa su universal, funciones encargadas cada una de una operación, pero equidistantes ambas, indiferenciadas en la unidad que engloba la conciencia absoluta. Esta conciencia real que reduce su influencia a lo meramente existente puede afirmar su eseidad gracias a la atribución que le transfiere el lado ideal, el polo limitante de la conciencia, que viene a su vez dado en función de la unidad suprema de la conciencia absoluta ${ }^{20}$. El mero lado ideal de la conciencia, como se había demostrado ya en el Vom Ich de 1795, era impotente para determinar por sí solo un saber completo porque él mismo era una pieza fundamental del conocimiento, pero en definitiva opuesta al elemento encargado de recibir los datos de la realidad, por tanto unilateral, y sobre estos dos elementos contrapuestos debía haber el acto originario de una conciencia absoluta que dominase, por medio de un acto libre e incondicionado, el mecanismo del intuir y del pensar ${ }^{21}$.

Cada cosa recibe su esencia específica por medio de la antítesis establecida con aquella diferencia que se le opone. Para el punto de vista absoluto aquella diferencia no queda recluida a la finitud, sino que la particularidad es entendida como esencia, es su quid lo que la inteligencia ha logrado extraer, y por tanto lo finito adquiere una naturaleza eterna, lo finito llega a ser idéntico a lo infinito, y con todo, es algo particular. Un objeto cohabita en la indiferencia del absoluto, y gracias a recibir su límite preciso por parte de la conciencia infinita, obtiene también la naturaleza que le permite desplegarse en el terreno de la existencia, aunque no parasitando la vida del absoluto, sino desplegándose por sí mismo en lo particular. Las cosas son, pero no pueden recibir el ser sin acoger las notas que le atribuyen el intuir y el pensar, dándose la abstracción del concepto con el que queda igualado con el resto de sus congéneres. A esta maniobra de la intuición se le llamará indistintamente cuerpo, así como a la labor de la razón se la denominará con el nombre de alma ${ }^{22}$. Lejos de la unidad absoluta, pero con la yerra indeleble del absoluto, aparecen las cosas en la finitud desde la que son contemplados por el hombre, y solo el hombre puede inteligir el universo desde esta plataforma.

\section{Centro o fundamento que confiere su inseparabilidad al cuerpo y al alma}

El empleo de los conceptos le permite al hombre dirigirse a cada cosa que no es él mismo, salir expulsado de sí mismo para comprender lo que queda fuera de él. Cuanto más acerado es el concepto con respecto a lo designado, el hombre más se divide a sí mismo en aquellas realidades que intenta traducir según sus conceptos, y por tanto más los conoce según su naturaleza, haciéndose más concorde con su carácter intelectivo. Sustrayéndose cada vez más de su particularidad, más fiel es a su naturaleza espiritual, y con más fidelidad se acerca al objeto que denota ${ }^{23}$. El hombre sigue siendo una criatura particular, pero solo él

20 S.W. III, p. 153-154.

21 Augusto, R.; "La libertad y el idealismo trascendental de Schelling", Agora 27/2, 2008, p. 67.

22 S.W. III, p. 155.

23 S.W. III, p. 125.

Daimon. Revista Internacional de Filosofía, Suplemento 5 (2016) 
y no otra entidad puede insuflar vida también a las ideas de aquellos objetos que adquieren por este proceso la misma independencia con respecto al hombre mismo. El hombre posee así una vida doble, en tanto que criatura independiente en sí mismo, y en tanto que criatura capaz de insuflar vida e independencia a otros productos igual que él, pero a los cuales, en cambio, él produce, mientras ellos no pueden intervenir en su producción.

El hombre es alma, en la misma medida que es cuerpo, pero por la primera de sus estructuras, es infinito, es espíritu, y esta disposición que procede de lo absoluto, le convierte en producto de lo absoluto. El hecho de que esta particular criatura finita tenga en sí también la posibilidad de recibir la esencia de todas las cosas, pudiendo vincular cada unidad con el eterno absoluto, le convierte en un ser afortunado que disfruta de la dicha divina, y que cuando está cerca de esta idea, más alejado está de su naturaleza individual. El hombre, como cualquier otro ser orgánico, recibe su individualidad de tal modo que cree poder subsistir por sí mismo. El cuerpo orgánico recibe una organización cerrada sobre sí misma de tal modo que adquiere vida por sí mismo y sin ningún tipo de dependencia de ningún apéndice de algo que no esté relacionado con su propia naturaleza, de modo que capaz de subsistir por sí mismo, se cree autónomo también con respecto a lo absoluto mismo. El hombre clausurado en su ipseidad olvida que toda criatura es relativa, que nada existe auténticamente sino gracias a su unidad con lo eterno ${ }^{24}$, y es solo en la medida en la que se acerca a lo infinito que adquiere toda su perfección, es decir, recala en su naturaleza, la de ser dependiente de un centro. El centro, o lo eterno, Dios, es la indiferencia de lo uno y lo múltiple. Aquello en cambio que no puede ser al mismo tiempo y a la vez los tres términos, es lo «nacido» ${ }^{25}$. De esta naturaleza es el hombre, pero a diferencia del resto de criaturas, el hombre puede encontrar radicada su unidad en el fundamento oculto de lo infinito. Cuando el hombre se comporta de este modo, adquiere la luz de un astro mismo, que es la esfera ígnea más perfecta del universo, la más dichosa de todas pero, tal como perfila esta estrella Schelling en su texto, un astro que se mueve en giro de traslación en torno a un astro más grande y absoluto que contiene cada una de las órbitas de los objetos celestes, sin seguir por eso ninguna de las rutas de estos planetas ${ }^{26}$ :

De esta naturaleza son los astros y todos los cuerpos celestes, cuyas ideas son las más perfectas de todas las que se hallan en Dios porque son las que más expresan aquel ser de lo finito cabe lo infinito en Dios.

Schelling aclara a qué se refieren dichas estrellas, y asegura que prefiere decir que son «animales dotados de sentido y entendimiento», cargados con un tiempo que es propio de su naturaleza orgánica constitutiva, pero también dotados de un alma de donde pueden extraer conceptos universales. En relación a aquella bestia que, dotada tan solo de sensibilidad no podía dar cuenta más que de su individualidad, este otro animal del que habla Schelling debe ser el hombre, una criatura carnal, pero también capaz de producir luz. Aquella imagen relativa a los movimientos orbitales además, que representa por un lado el carácter 
móvil del pensar, donde se cifra así mismo el fluir del tiempo por el que discurre y que le relaciona con su realidad material, gracias a lo cual adquiere una naturaleza «dinámica, infinita, activa» ${ }^{27}$, es lo que representa y debe denominarse autoconciencia, que se produce por medio de la unión de lo finito con lo infinito, de modo que sin la ayuda de Dios, de donde procede el fundamento de la existencia del hombre, el hombre carecería de aquello que lo hace distintivamente hombre, su naturaleza infinita, aquella que le permite transitar por la realidad de cada cosa pero que, en el momento en el que el orden de adecuación tiene lugar, no se produce ya con respecto a la existencia vacía, sino con respecto a la idea de la que procede el patrón que le otorga su existencia a lo particular. Aquel conocimiento entonces es un saber racional, que se trata de «la imagen más inmediata de lo eterno» ${ }^{28}$. Cuando esta criatura celeste que es el hombre es capaz de representar fielmente lo particular por medio de conceptos infinitos, y logra expresar lo finito bajo la forma de la idea, el hombre es capaz de simultanear su existencia corporal, sin sufrir ningún tipo de menoscabo, y al mismo tiempo hacerlo de un modo absoluto ${ }^{29}$. Cuerpo y alma no se oponen en una pugna irresoluble, como le ocurre a Fichte en su diseño de la relación del cuerpo con respecto al alma $^{30}$, sino que entran en una concordancia armónica en tanto que atienden a un principio que permite sujetar al cuerpo y al alma unidos bajo un centro o un fundamento primero, o para ser, más exactos, bajo un fundamento "cero".

La propiedad infinita del alma aborda espontáneamente lo finito, tiene la facultad, sencillamente, de «representar el cuerpo» ${ }^{31}$, de atribuir contenido a los datos que el cuerpo presenta, y colocándose como instancia infinita de lo que de particular conocemos, el alma se sitúa en la posición de genitivo del cuerpo, siendo este último lo individual que, no obstante, se pone como idéntico a la infinitud por medio del alma. El cuerpo permite que el alma obtenga alguna expresión concreta, gracias a que el alma comunica al cuerpo de manera inmediata su concepto, tendiéndose entre los dos lo eterno por lo que alma y cuerpo devienen una unidad. Finitud e infinitud devienen uno en el individuo particular, devienen «necesidad infinita» ${ }^{32}$, fusión de necesidad y libertad en el sujeto concreto.

El alma, reflejo directo de la razón, podría mostrar inmediatamente las determinaciones del universo de manera consecutiva. Pero recluida en los límites del cuerpo celeste que es el hombre, no puede abordar semejante empresa sin obstáculos, sino que su tarea es más humilde, teniendo que hallar metódicamente cada determinación tal como ordena el proceso del conocimiento finito a que fuerza el límite marcado por la sustancia corpórea, hasta llegar paulatinamente a conceptos precisos. Se trata de un modo de conocer especulativo, si nos permite introducir esta expresión la metáfora empleada por Schelling según la cual nosotros «conocemos aquí solo como a través de un espejo» ${ }^{33}$. El alma por tanto, que tiene la facultad de conocer infinitamente, debe hacerlo en cambio representando ilimitadamente las cosas sometidas al tiempo. Un alma así no estará menos sometida al tiempo. Pero a la vez

27 S.W. III, p. 161.

28 S.W. III, p. 163.

29 S.W. III, p. 163.

30 Fichte, G.F.; Doctrina de la ciencia nova methodo, Valencia, Natán, 1987, p. 144.

31 S.W. III, p. 177.

32 S.W. III, p. 190.

33 S.W. III, p. 180.

Daimon. Revista Internacional de Filosofía, Suplemento 5 (2016) 
el alma es el conocer infinito, una pieza indispensable de la capacidad omnímoda de Dios, pero solo una parte. Debe introducirse pues una concepción dual de alma: 1) un alma finita, cuando la vemos referirse a las cosas de las que pueden abstraerse conceptos determinados; y 2) un alma infinita, que responde estrictamente a su capacidad eterna de conocer. El alter ego de Schelling en el diálogo, Bruno, resumirá esta relación diciendo que la primera es «el concepto infinito del conocer», y la segunda «el conocer objetivamente existente» ${ }^{34}$. Ambas piezas constituyen la unidad indisoluble del pensar y el intuir, así como el pensar sin el intuir produciría fantasmas terribles y el intuir sin el pensar cuerpos amorfos, o como el alma sin el cuerpo, y éste sin el primero, sería un objeto muerto ${ }^{35}$. Dado que el alma no puede poner en acto su posibilidad infinita de conocer sin los límites que le imponen el cuerpo, el alma infinita y el alma finita viven apaciguadamente en el cuerpo y son uno, pero el alma infinita dentro de este límite está recordando constantemente su origen ilimitado, eterno, su procedencia divina. Cuando todo se mueve de modo concorde a este modelo, los planetas realizan sus órbitas tal como dicta el motor rector, pero ese movimiento, aunque realizado tal como le dicta su propia naturaleza, en cambio es impulsado gracias al arrastre atractivo del Sol. Hay aquí posibilidad de conocer aquella necesidad destilada por Dios mismo, y la posibilidad de conocer sus efectos, «lo que pertenece al reflejo» ${ }^{36}$, algo facilitado por la actividad del pensamiento que reside en el alma, y las cualidades y determinaciones materiales radicadas en los límites impuestos por el cuerpo. Así, aunque la ipseidad del intelecto depositada en el hombre, reducida a los límites del cuerpo material y orgánico, puedan dar la idea de una independencia radical, pues el organismo, como se vio, es una unidad subsistente por sí sola, en cambio el conjunto de su identidad reside en un foco distinto. El hombre, siendo una figura central de la creación, no puede en cambio constituir ningún centro ${ }^{37}$ :

[...] el conocer absoluto, aun estando eternamente en Dios y siendo Dios mismo, no puede sin embargo pensarse como actividad. Pues alma y cuerpo, esto es, actividad y ser son sus propias formas, que no están en él sino bajo él.

\section{Bibliografía}

Fuentes originales

Schellings Werke, (1927-1954): M. Schröter. C.H. Beck/ R. Oldenburg, München (= Münchener Jubilämsdruck).

Traducciones al español

Schelling, F.W.J. (1985): Bruno o sobre el principio divino y natural de las cosas, Orbis, Barcelona.

Schelling, F.W.J. (2012): “Sistema del Idealismo trascendental”, en Schelling, Gredos, Madrid.

34 S.W. III, p. 183.

35 S.W. III, p. 188-189.

36 S.W. III, p. 193.

37 S.W. III, p. 201. 
Fuentes primarias

Fichte, G.F. (1987): Doctrina de la ciencia nova methodo, Natán, Valencia.

Fuentes secundarias

Augusto, R. (2008): "La libertad y el idealismo trascendental de Schelling", Agora 27/2, pp. 63-85.

Wieshuber, A. (2013): "Del sistema de la libertad al diagrama del poder. Reflexiones estéticas a partir de la Filosofía del Arte de Schelling", El fondo de la historia. Estudios sobre Idealismo alemán y Romanticismo, (Madrid), Carrasco Conde, A. y Gómez Ramos, A. (eds.), Dykinson, pp. 51-60. 